Article

\title{
Virulence Genes as Markers for Pseudomonas aeruginosa Biofilm Formation in Dogs and Cats
}

\author{
Daria Płókarz ${ }^{1}$, Michał Czopowicz ${ }^{2}$ (D) Karolina Bierowiec ${ }^{1}$ and Krzysztof Rypuła ${ }^{1, *(D)}$ \\ 1 Division of Infectious Diseases of Animals and Veterinary Administration, Department of Epizootiology and \\ Clinic of Birds and Exotic Animals, Faculty of Veterinary Medicine, Wroclaw University of Environmental \\ and Life Sciences, pl. Grunwaldzki 45, 50366 Wroclaw, Poland; daria.plokarz@upwr.edu.pl (D.P.); \\ karolina.bierowiec@upwr.edu.pl (K.B.) \\ 2 Division of Veterinary Epidemiology and Economics, Institute of Veterinary Medicine, Warsaw University of \\ Life Sciences-SGGW, Nowoursynowska 159c, 02776 Warsaw, Poland; mczopowicz@gmail.com \\ * Correspondence: krzysztof.rypula@upwr.edu.pl; Tel.: +48-71-3205-326
}

check for

updates

Citation: Płókarz, D.; Czopowicz, M.; Bierowiec, K.; Rypuła, K. Virulence Genes as Markers for Pseudomonas aeruginosa Biofilm Formation in Dogs and Cats. Animals 2022, 12, 422 https://doi.org/10.3390/ ani12040422

Academic Editor:

Olga Szaluś-Jordanow

Received: 6 December 2021

Accepted: 8 February 2022

Published: 10 February 2022

Publisher's Note: MDPI stays neutral with regard to jurisdictional claims in published maps and institutional affiliations.

Copyright: (C) 2022 by the authors. Licensee MDPI, Basel, Switzerland. This article is an open access article distributed under the terms and conditions of the Creative Commons Attribution (CC BY) license (https:// creativecommons.org/licenses/by/ $4.0 /)$.
Simple Summary: Pseudomonas aeruginosa is an opportunistic pathogen of dogs and cats able to cause both local and systemic infections. This bacterium is widespread in the environment, resistant to unfavorable conditions, and may spread between humans and other mammals. Its virulence and transmission rely on various virulence factors including those responsible for biofilm formation. Biofilm is defined as a complex biological system that is composed of exopolysaccharides, proteins, extracellular DNA, and biomolecules. Extracellular polymeric substances are the main ingredients of biofilm, accounting for $90 \%$ of its total biomass. In this study we analyzed the prevalence of five virulence genes involved in biofilm formation (pelA, pslA, ppyR, fliC and nan1) in 271 P. aeruginosa isolates obtained from dogs and cats. All animals had clinical symptoms of P. aeruginosa infection. In dogs, the strains were isolated from the external auditory canal, respiratory tract, and skin. In cats, the strains were isolated from the nasal cavity, external auditory canal, and skin. Biofilm-forming strains accounted for $90.6 \%$ of $P$. aeruginosa isolates from dogs and $86.4 \%$ from cats. The most commonly identified virulence factor gene was ppyR (97.4\%). The fliC and pslA genes were detected in $62.4 \%$ and $60.1 \%$ of the study population, respectively, whereas nan 1 and pelA genes were found in $45.0 \%$ and $38.7 \%$, respectively. Prevalence of the virulence factor genes was not significantly different between dogs and cats. Given that the ability to form biofilm is related to the antibiotic resistance of $P$. aeruginosa, our results indicate potential candidates for biomarkers assisting in selection of the most effective treatment for $P$. aeruginosa infections.

\begin{abstract}
Pseudomonas aeruginosa is an ubiquitous bacterium and opportunistic pathogen that plays an important role in nosocomial infections. The presence of virulence factors and the biofilm-forming ability of this species contributes to a high risk of treatment complications. In this study, we examined the biofilm-forming ability and the prevalence of five virulence factor genes (pslA, pelA, ppyR, fliC, and nan1) in 271 P. aeruginosa isolates (212 from dogs and 59 from cats). Biofilm-forming ability was detected in $90.6 \%$ of isolates in dogs and $86.4 \%$ of isolates in cats. In P. aeruginosa isolates from both species, the most prevalent virulence factor gene was ppyR $(97.2 \%$ in dogs and $98.3 \%$ in cats), followed by pslA ( $60.8 \%$ and $57.6 \%)$, fliC (60.4\% and $69.5 \%)$, nan $1(45.3 \%$ and $44.1 \%)$, and pelA ( $40.1 \%$ and $33.9 \%$, respectively). In dogs, a significantly higher proportion of biofilm-forming $P$. aeruginosa strains possessed the fliC gene compared to non-biofilm-forming strains $(p=0.015)$. In cats, a significantly lower proportion of biofilm-forming strains had the nan1 gene compared to non-biofilm-forming strains $(p=0.017)$. In conclusion, the presence of fliC gene and the absence of nan1 gene could be indicators of biofilm-forming ability of $P$. aeruginosa.
\end{abstract}

Keywords: biofilm; Pseudomonas aeruginosa; virulence genes; dogs; cats 


\section{Introduction}

Pseudomonas aeruginosa (P. aeruginosa) is a ubiquitous Gram-negative bacillus. It is also an opportunistic pathogen that occurs on the skin and mucosal membranes of humans and other mammals. In dogs and cats, P. aeruginosa causes skin, systemic and urinary tract infections [1], as well as ulcers, hemorrhagic crusts, erythematous papules [2], otitis externa [3], conjunctivitis [4], rhinosinusitis [5], periapical tooth abscesses [6], and periodontal disease [7]. These infections are consistent with the "One Health" concept, because of the bacterium persistence in the environment, and possible transmission between humans and other mammals.

Biofilm is defined as a complex biological system that is composed of exopolysaccharides, proteins, extracellular DNA, and biomolecules [8]. Extracellular polymeric substances (EPS) are the main ingredients of biofilm, forming 50-90\% of total biofilm biomass [3]. $P$. aeruginosa with biofilm-forming ability colonize both biotic and abiotic surfaces. The increasing number of experiments on this subject confirm that chronic infection is caused by bacterial biofilm formation, rather than the planktonic form of bacteria, which causes acute infection [9]. The quorum-sensing system controls the ability of flagellated microorganisms to transform from the planktonic into the biofilm form [8].

The various mechanisms involved in biofilm formation are related to the production of virulence factors, which are encoded by established genes. Crucial components of the biofilm structure are the exopolysaccharide containing components Psl and Pel. Pel is required to form biofilm on solid surfaces; on the other hand, Psl regulates adhesion to solid surfaces and initiates biofilm growth by developing new microcolonies $[10,11]$. The pslA and pelA genes participate in the formation of the carbohydrate-rich structure of the biofilm matrix. Moreover, after inactivation of the ppyR gene, the Psl operon is suppressed and a decline in biofilm formation occurs. The ppyR gene encodes a putative transmembrane protein. The fliC gene is a crucial component of flagella production, due to subunit protein-encoding-flagellin type B [12]. Flagella are highly immunogenic, and are essential for inflammation development [13]. Flagellin P. aeruginosa strains releases epithelial TLR5 signaling NF-kB. Flagellum mediated-swimming is one of several types of motilities in P. aeruginosa strains. The mutants of $P$. aeruginosa that do not have flagella have poor colonization ability [12].

Another virulence factor is neuraminidase, which is an extracellular factor involved in the implantation of $P$. aeruginosa. Neuraminidase may upregulate a number of potential bacterial receptors and it might release terminal sialic acid residues from sialylated gangliosides [14,15]. Wolska et al. [16] obtained a statistically significant difference in the adhesion of buccal epithelial cells in $P$. aeruginosa strains that contained one neuraminidase encoding gene (nan1) versus strains in which nan1 was not detected.

In this study we aimed to analyze the prevalence of five virulence factor genes (pelA, pslA, ppyR, fliC, and nan1) that could affect biofilm formation in P. aeruginosa strains from dogs and cats.

\section{Materials and Methods}

This study included 271 isolates collected from dogs $(n=212)$ and cats $(n=59)$ in the Lower Silesia, Poland, between 2017 and 2020. Male-to-female ratio was close to 1 . The age of animals ranged from 2 months to 18 years (median of 7 years) and was significantly higher in dogs than in cats $(p=0.001)$. Pedigree individuals accounted for $80 \%$ of dogs, whereas the domestic shorthair breed predominated among cats (Table 1). All animals had clinical symptoms of $P$. aeruginosa infection, which was confirmed in microbiological tests. In dogs, the external auditory canal was the most common collection site, followed by the respiratory system, and skin. In cats, most of $P$. aeruginosa strains were isolated from the nasal cavity. These strains were significantly more often isolated from the external auditory canal, skin, and appendages of dogs, and from the respiratory tract of cats (Table 1). 
Table 1. Demographic characteristics of the study population and collection sites of $P$. aeruginosa strains isolated from dogs and cats.

\begin{tabular}{|c|c|c|c|c|}
\hline Characteristic & Overall $(n=271)$ & Dogs $(n=212)$ & Cats $(n=59)$ & $p$-Value \\
\hline \multicolumn{5}{|c|}{ Demographic Characteristics } \\
\hline Age $^{\text {a }}$ (years) & $7,4-10(0.2-18)$ & $7,4-10(0.7-18)$ & $5,1-8(0.2-16)$ & $0.001 *$ \\
\hline Male sex (n (\%)) & $146(53.9)$ & $112(52.8)$ & $34(57.6)$ & 0.513 \\
\hline Breed (n (\%)) & & & & \multirow{9}{*}{$<0.001$ * } \\
\hline Crossbreed/Domestic shorthair & - & $43(20.3)$ & $43(72.9)$ & \\
\hline Pedigree & - & $169(79.7)$ & $16(27.1)$ & \\
\hline German Shepherd & - & 33 & - & \\
\hline Cocker spaniel & - & 25 & - & \\
\hline Beagle & - & 12 & - & \\
\hline Golden retriever & - & 10 & - & \\
\hline Shih-tzu & - & 10 & - & \\
\hline Others & - & 79 & - & \\
\hline \multicolumn{5}{|c|}{ Collection site } \\
\hline External auditory canal & $121(44.6)$ & $118(55.7)$ & $3(5.1)$ & $<0.001 *$ \\
\hline Respiratory system and oral cavity & $85(31.4)$ & $36(17.0)$ & $49(83.1)$ & \multirow{6}{*}{$<0.001$ * } \\
\hline Nasal cavity & 51 & 7 & 44 & \\
\hline Conjunctival sac & 12 & 10 & 2 & \\
\hline Throat & 10 & 8 & 2 & \\
\hline Trachea and bronchi & 7 & 6 & 1 & \\
\hline Oral cavity & 5 & 5 & 0 & \\
\hline Skin and appendages & $33(12.2)$ & $31(14.6)$ & $2(3.4)$ & \multirow{3}{*}{$0.020 *$} \\
\hline Skin & 27 & 25 & 2 & \\
\hline Perianal glands & 6 & 6 & 0 & \\
\hline Wounds & $20(7.4)$ & $16(7.5)$ & $4(6.8)$ & 0.855 \\
\hline Genito-urinary tract & $11(4.1)$ & $10(4.7)$ & $1(1.7)$ & \multirow{3}{*}{0.301} \\
\hline Vagina & 7 & 7 & 0 & \\
\hline Urine & 4 & 3 & 1 & \\
\hline Joint fluid & $1(0.4)$ & $1(0.5)$ & 0 & 0.586 \\
\hline
\end{tabular}

a data available for 173 dogs and 43 cats; presented as the median, interquartile range, and range; ${ }^{*}$ significant at $\alpha=0.05$.

\subsection{Isolates}

The isolates of non-fermentative gram-negative bacilli were transferred to basic media. All isolates were cultured on a Columbia Blood Agar Base Thermo Scientific OXOID with 5\% sheep blood and MacConkey Agar (Thermo Scientific OXOID, Gdańsk, Poland). The isolates were then checked for oxidase production (Oxidase Detection Strips MICROGEN MID-61g GRASO BIOTECH, Starogard Gdański, Poland). Isolates were frozen with Brain Heart Infusion Broth (BHI) (Thermo Scientific OXOID, Gdańsk, Poland) supplemented with $30 \%$ glycerol.

\subsection{DNA Extraction}

Oxidase positive isolates were cultured on a Columbia Blood Agar Base with $5 \%$ sheep blood (Thermo Scientific OXOID, Gdańsk, Poland) and were incubated overnight at $37^{\circ} \mathrm{C}$. A few colonies from each strain were added to $200 \mu \mathrm{L}$ distilled water, shaken, and boiled for $20 \mathrm{~min}$. The samples were then frozen at $-20{ }^{\circ} \mathrm{C}$ for $5 \mathrm{~min}$. After deactivation, the suspensions were centrifuged at 13,000 rpm for $3 \mathrm{~min}$. The supernatant was preserved as template DNA. 


\subsection{PCR Assay}

After pre-selection, isolates with $P$. aeruginosa identification were confirmed by polymerase chain reaction (PCR) based on amplification of two outer membrane lipoproteins genes, oprI and oprL. OprL encodes lipoprotein specific for P. aeruginosa, and oprI encodes lipoprotein which occur in both other fluorescent pseudomonads and P. aeruginosa [17].

The DNA was amplified in a thermocycler (Bio-Rad, Marnes-la-Coquette, France), using modified methods. The methods and primers are presented in Table 2.

Table 2. PCR assay reaction conditions and primers used in this study.

\begin{tabular}{|c|c|c|c|}
\hline Target Genes & Primer Sequence $5^{\prime}-3^{\prime}$ & Product Size (bp) & Reference \\
\hline pslA & $\begin{array}{l}\text { F: 5'-TCCCTACCTCAGCAGCAAGC-3' } \\
\text { R: } 5^{\prime}-\mathrm{TGTTGTAGCCGTAGCGTTTCTG-3'}\end{array}$ & 656 & Ghadaksaz et al., 2015 [18] \\
\hline pelA & $\begin{array}{c}\text { F: 5'-CATACCTTCAGCCATCCGTTCTTC-3' } \\
\text { R: 5'-CGCATTCGCCGCACTCAG-3' }\end{array}$ & 786 & Ghadaksaz et al., 2015 [18] \\
\hline ppyR & $\begin{array}{l}\text { F: 5'-CGTGATCGCCGCCTATTTCC-3' } \\
\text { R: 5'-ACAGCAGACCTCCCAACCG-3' }\end{array}$ & 160 & Ghadaksaz et al., 2015 [18] \\
\hline fliC & $\begin{array}{l}\text { F: 5'-TGAACGTGGCTACCAAGAACG-3' } \\
\text { R: 5'-TCTGCAGTTGCTTCACTTCGC-3' }\end{array}$ & 180 & Immani et al., 2009 [19] \\
\hline nan1 & $\begin{array}{l}\text { F: 5'-ACGCTCCGTCCAGCCGGA-3' } \\
\text { R: 5'-GTCTGGACGACGGCGGCA-3' }\end{array}$ & 221 & Lanotte et al., 2004 [14] \\
\hline oprI & $\begin{array}{c}\text { F: 5'ATGAACAACGTTCTGAAATTCTCTGCT-3' } \\
\text { R: 5'-CTTGCGGCTGGCTTTTTCCAG-3' }\end{array}$ & 249 & De Vos et al., 1997 [17] \\
\hline oprL & $\begin{array}{l}\text { F: 5'-ATGGAAATGCTGAAATTCGGC-3' } \\
\text { R: 5'-CTTCTTCAGCTCGACGCGACG-3' }\end{array}$ & 504 & De Vos et al., 1997 [17] \\
\hline
\end{tabular}

Genes were amplified using $2.5 \mu \mathrm{L}$ buffer ( $\mathrm{MgCl}_{2}$ at $20 \mathrm{mM}$ concentration), $0.2 \mu \mathrm{L}$ Taq DNA Polymerase (5 U/L) (Thermo Fischer Scientific, Vilnius, Lithuania), $0.2 \mu \mathrm{L}$ dNTP Mix 10 (Thermo Fischer Scientific, Vilnus, Lithuania), $0.2 \mu \mathrm{L}$ of each specific primer created by Genomed S.A. (Warsaw, Poland) (Table 2), and $2 \mu \mathrm{L}$ template DNA. The solution was increased to a $25 \mu \mathrm{L}$ volume with sterile water.

Electrophoresis was performed in 2\% Agarose gel with Midori Green (NIPPON Genetics EUROPE, Düren, Germany), and Marker 2 (A\&A Biotechnology, Gdańsk, Poland) was used as a DNA ladder and detected by UV transillumination (Bio-Rad, Marnes-la-Coquette, France). Genetic material of P. aeruginosa ATCC 27853 strain was used as a positive control, and Mili Q water as a negative control.

\subsection{Microtiter Plate Method}

The microtiter plate method (MTP) was performed following the method of $\mathrm{O}^{\prime}$ Toole et al. [20]. Pure colonies of strains were cultured on Columbia Agar with 5\% sheep blood, after overnight incubation at $37^{\circ} \mathrm{C}$. A few colonies were diluted in a $\mathrm{BHI}$ broth, and incubated at $37^{\circ} \mathrm{C}$ overnight. This culture was made equal with 0.5 McFarland standard, and was then diluted at a ratio of 1:100 in fresh a BHI medium. Then, $200 \mu \mathrm{L}$ of the solution was added to a 96-well sterile microtiter plate. Each sample of P. aeruginosa isolate was replicated in eight wells. The fresh BHI broth was used as a negative quality control. Plates were incubated for $24 \mathrm{~h}$ at $37^{\circ} \mathrm{C}$. Then, the plate was turned over and the broth was shaken out. Next, water was gently added to each well and shaken out. This protocol was repeated twice. Then, $250 \mu \mathrm{L}$ of a $0.1 \%$ solution of Cristal Violet, was added to each well. The microtiter plate was incubated at room temperature for $10 \mathrm{~min}$, and was then washed three times by submerging it in a tube of water, and shaking it. The plate was left upside down for a few hours to dry completely [20]. Biofilm was quantified using the modified MTP method [21]. To each well, $250 \mu \mathrm{L}$ of $95 \%$ ethanol was added to solubilize the crystal 
violet. Absorbance was measured (Spark 10M) at $590 \mathrm{~nm}$. Sterile BHI was used as a negative control. P. aeruginosa ATCC 27853 with the capacity to form biofilm was used as a positive control. Biofilm-formation ability was considered as positive at a cut-off level 0.269 . We determined cut-off arbitrarily by the mean for the negative control (culture medium, 0.149) plus two standard deviations (0.06). Levels of biofilm production were established based on following classification criteria: weak biofilm formers: $0.269<$ A590 < 0.538 ( $2 \times$ negative controls); moderate biofilm formers: $0.538<$ A590 < 1.076 ( $4 \times$ negative controls); strong biofilm formers: $1.076<$ A590 $(6 \times$ negative controls $)$.

\subsection{Statistical Analysis}

Categorical variables were expressed as counts in groups and percentages from the study population and compared between groups using the maximum likelihood G-test or Fisher's exact test if an expected count in any cell of the contingency table was below 5 . Proportions were compared between ordinal classes (strength of biofilm-forming ability) using the $\chi^{2}$ test for trends [22]. The 95\% confidence interval (CI 95\%) for proportions (prevalence) was calculated using the Wilson score method [23]. Numerical variables were presented as the median, interquartile range (IQR), and range, and compared between groups using the Mann-Whitney $U$ test. The same test was used to compare ordinal variables (strength of biofilm-forming ability) between groups. Correlations between ordinal and numerical variables were analyzed using the Spearman's rank correlation coefficient $\left(R_{S}\right)$. All tests were two-tailed. A significance level $(\alpha)$ was set at 0.05 . Statistical analysis was performed using TIBCO Statistica 13.3 (TIBCO Software Inc., Palo Alto, CA, USA).

\section{Results}

Biofilm-forming strains accounted for $90.6 \%$ (CI 95\%: $85.9 \%-93.8 \% ; n=192$ ) of P. aeruginosa isolates from dogs, and $86.4 \%$ (CI 95\%: 75.5\%-93.0\%; $n=51$ ) of P. aeruginosa isolates from cats. Proportions of biofilm-forming strains with weak $(n=64 ; 26.3 \%$ of 243 biofilmforming strains), intermediate $(n=85 ; 35.0 \%)$, and strong $(n=94 ; 38.7 \%)$ biofilm-forming ability were similar, and their distribution was not significantly different between dogs and cats $(p=0.893)$ (Figure 1$)$.

The prevalence of biofilm-forming strains did not significantly differ between males and females (dogs: $90.2 \%$ vs. $91.0 \%$, respectively, $p=0.838$; cats: $91.2 \%$ vs. $80.0 \%$, respectively, $p=0.265)$ or among collection sites either in dogs $(p=0.092)$ or in cats $(p=0.999)$ (Table 3).

Table 3. Biofilm-forming Pseudomonas aeruginosa strains isolated from various collection sites.

\begin{tabular}{|c|c|c|}
\hline \multirow{2}{*}{ Collection Site } & \multicolumn{2}{|c|}{ Biofilm-Forming $P$. aeruginosa Strains } \\
\hline & No. of Strains & Prevalence (CI 95\%) \\
\hline \multicolumn{3}{|c|}{ Dogs $(n=212)$} \\
\hline External auditory canal $(n=118)$ & 111 & $94.1(88.3-97.1)$ \\
\hline Skin and appendages $(n=31)$ & 28 & $90.3(75.1-96.7)$ \\
\hline Respiratory system and oral cavity $(n=36)$ & 28 & $77.8(61.9-88.3)$ \\
\hline Genito-urinary tract $(n=10)$ & 10 & $100(72.2-100)$ \\
\hline Wounds $(n=16)$ & 14 & $87.5(64.0-96.5)$ \\
\hline \multicolumn{3}{|c|}{ Cats $(n=59)$} \\
\hline Respiratory system $(n=49)$ & 42 & $85.7(73.3-92.9)$ \\
\hline Others $(n=10)$ & 9 & $90.0(59.6-98.2)$ \\
\hline
\end{tabular}




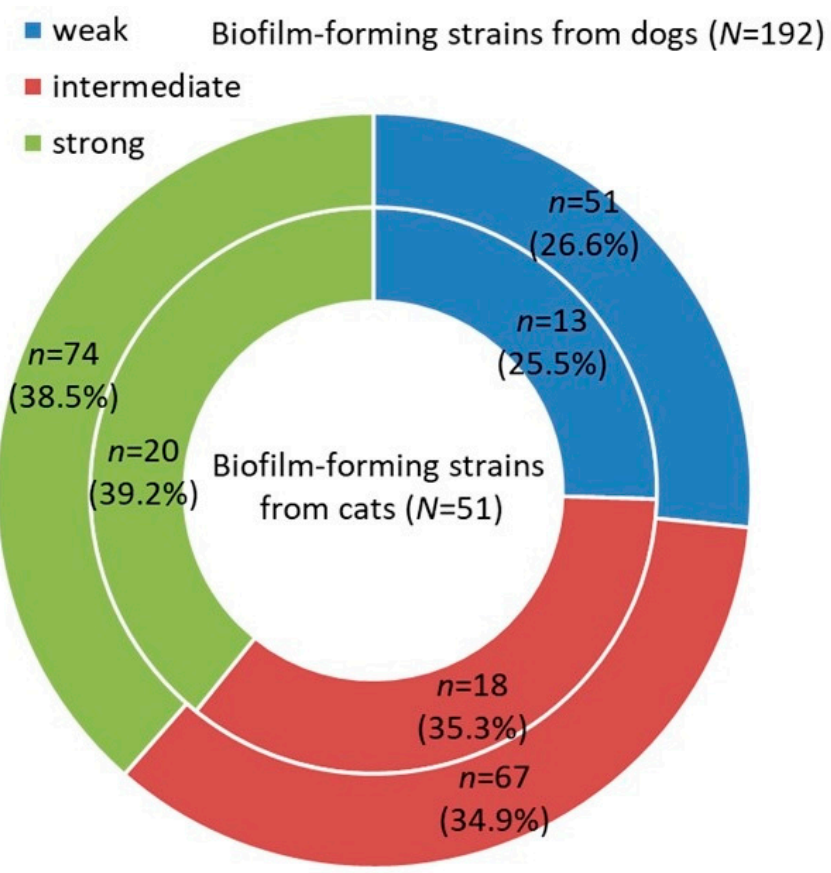

Figure 1. Proportion of biofilm-forming strains with various strength of biofilm-forming ability (weak, intermediate, and strong) isolated from dogs (outer cycle) and cats (inner cycle).

The strength of biofilm-forming ability was neither different between sexes $(p=0.731$ in dogs and $p=0.934$ in cats) nor correlated with animals' age either in dogs $\left(R_{\mathrm{s}}=0.11\right.$; $p=0.148)$ or in cats $\left(R_{\mathrm{s}}=0.29 ; p=0.059\right)$.

The most commonly identified virulence factor gene was ppyR $(n=264 ; 97.4 \%, \mathrm{CI}$ 95\%: 94.8\%-98.7\%). The fliC ( $n=169 ; 62.4 \%$, CI 95\%: 56.5\%-67.9\%) and pslA $(n=163$; $60.1 \%$, CI 95\%: 54.2\%-65.8\%) genes were detected significantly less often, whereas nan1 $(n=122 ; 45.0 \%$, CI 95\%: $39.2 \%-51.0 \%)$ and pelA $(n=105 ; 38.7 \%$, CI $95 \%: 33.1 \%-44.7 \%)$ genes were observed in the lowest proportion of isolates. Prevalence of the five virulence factor genes was not significantly different between dogs and cats (Figure 2).

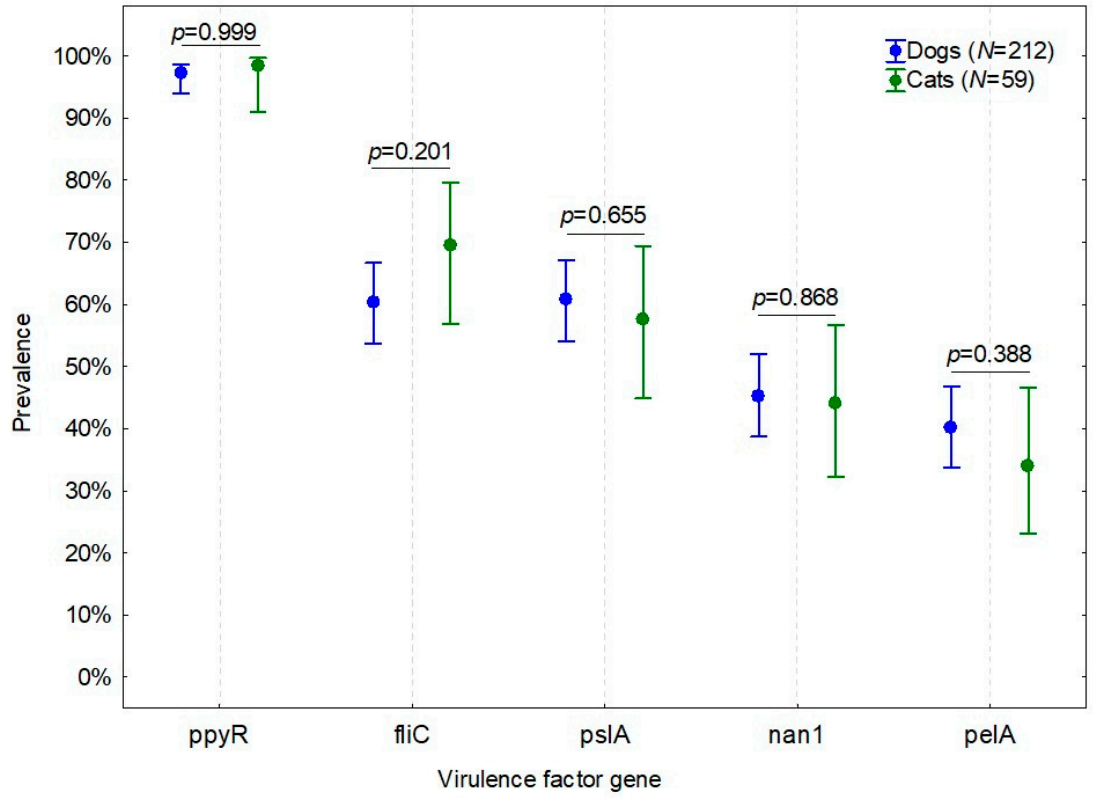

Figure 2. Prevalence (CI 95\%) of virulence factor genes in P. aeruginosa strains isolated from dogs and cats. 
The only virulence factor genes whose prevalence significantly differed between biofilm-forming and non-biofilm-forming P. aeruginosa strains were the fliC gene in dogs (significantly more often detected in biofilm-forming $P$. aeruginosa strains; $p=0.015$ ) and nan 1 gene in cats (significantly less often detected in biofilm-forming P. aeruginosa strains; $p=0.017$ ) (Table 4).

Table 4. Prevalence of virulence factor genes in 192 biofilm-forming and 20 non-biofilm-forming P. aeruginosa strains from dogs, and 51 biofilm-forming and 8 non-biofilm-forming P. aeruginosa strains from cats.

\begin{tabular}{|c|c|c|c|c|c|}
\hline \multirow{3}{*}{ Virulence Factor Gene } & \multicolumn{4}{|c|}{ Pseudomonas aeruginosa Strains } & \multirow{3}{*}{$p$-Value } \\
\hline & \multicolumn{2}{|c|}{ Biofilm-Forming } & \multicolumn{2}{|c|}{ Non-Biofilm-Forming } & \\
\hline & $n$ & Prevalence (CI 95\%) & $n$ & Prevalence (CI 95\%) & \\
\hline \multicolumn{6}{|c|}{ Dogs } \\
\hline pslA & 117 & $60.9(53.9-67.6)$ & 12 & $60.0(38.7-78.1)$ & 0.935 \\
\hline pelA & 76 & $39.6(32.9-46.6)$ & 9 & $45.0(25.8-65.8)$ & 0.638 \\
\hline ppyR & 186 & $96.9(93.4-98.6)$ & 20 & $100(83.9-100)$ & 0.999 \\
\hline fliC & 121 & $63.0(56.0-69.5)$ & 7 & $35.0(18.1-56.7)$ & $0.015^{*}$ \\
\hline nan1 & 88 & $45.8(38.9-52.9)$ & 8 & $40.0(21.9-61.3)$ & 0.617 \\
\hline \multicolumn{6}{|c|}{ Cats } \\
\hline pslA & 29 & $56.9(43.3-69.5)$ & 5 & $62.5(30.6-86.3)$ & 0.999 \\
\hline pelA & 17 & $33.3(22.0-47.0)$ & 3 & $37.5(13.7-69.4)$ & 0.999 \\
\hline ppyR & 50 & $98.0(89.7-99.7)$ & 8 & $100(67.6-100)$ & 0.999 \\
\hline flic & 35 & $68.6(55.0-79.7)$ & 6 & $75.0(40.9-92.9)$ & 0.999 \\
\hline nan1 & 19 & $37.3(25.3-51.0)$ & 7 & 87.5 (52.9-97.8) & 0.017 * \\
\hline
\end{tabular}

* significant at $\alpha=0.05$.

Only the prevalence of nan1 gene appeared to be significantly linked to the strength of biofilm-forming ability. A significantly lower proportion of strains with strong biofilmforming ability than strains with weak and moderate biofilm-forming ability had nan1 gene $(p=0.022)$ (Figure 3).

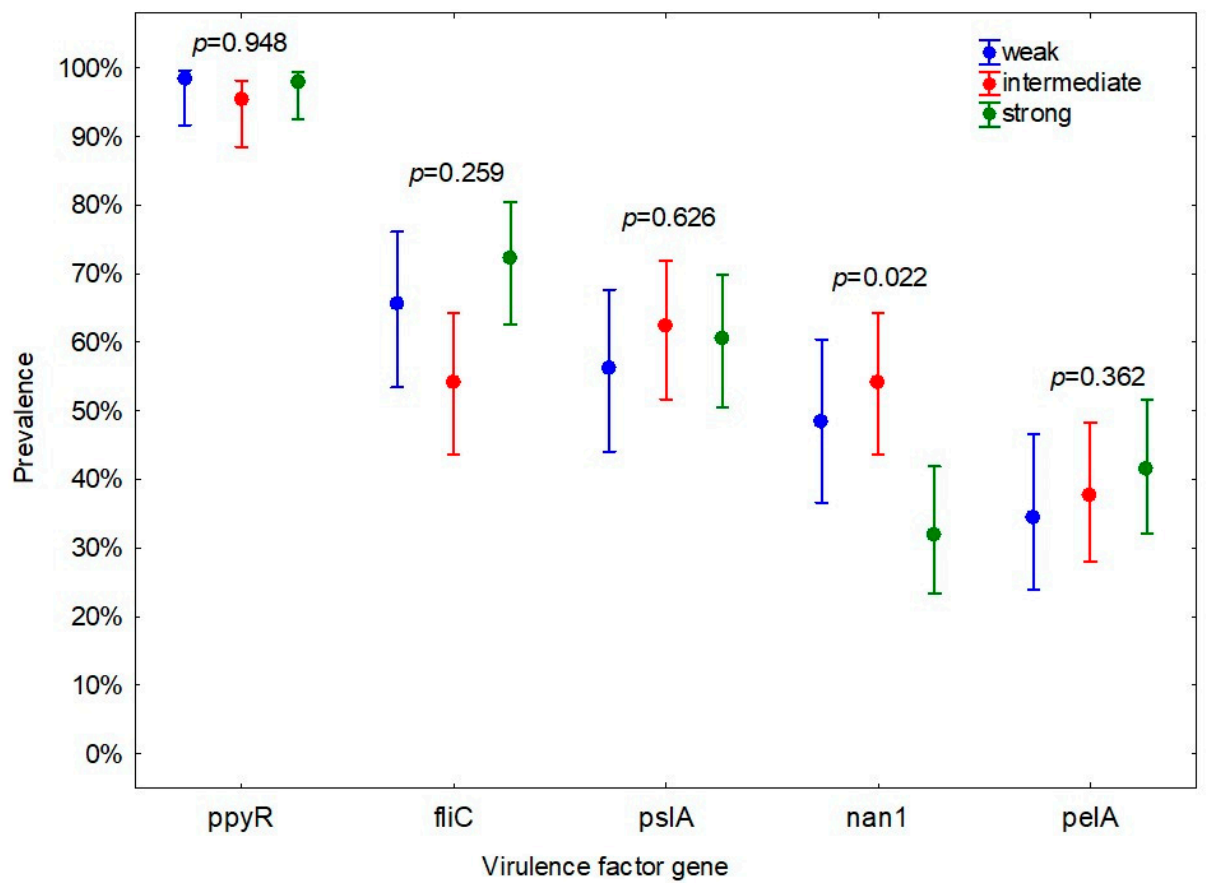

Figure 3. Prevalence (CI 95\%) of virulence factor genes in biofilm-forming Pseudomonas aeruginosa strains with weak $(n=64)$, intermediate $(n=85)$, and strong $(n=94)$ biofilm-forming ability. 


\section{Discussion}

Biofilm formation is the most important virulence factor of P. aeruginosa and is often responsible for failures of the antibiotic treatment. Antibiotic resistance is higher among biofilm-forming strains compared to strains without this property. Commercial methods for testing antibiotic susceptibility rely on the minimum inhibitory concentration (MIC). However, this approach is only feasible for the planktonic phase of bacteria. Consequently, if clinicians do not know which phase of bacteria (planktonic versus biofilm-forming) is being examined, MIC indication may be misleading. Proper selection of antibiotic therapy in $P$. aeruginosa infection with the strain bearing virulence factor requires the minimum biofilm eliminating concentration (MBEC) be determined or additional biofilm removing substance be applied [24]. Analysis of cases with biofilm-forming Pseudomonas spp. strains shows that the MBEC should be determined [24,25]. Microbiological methods verifying $P$. aeruginosa biofilm-forming ability are time-consuming and require specific equipment and trained laboratory staff. Our study aimed at finding an easier and faster way to confirm $P$. aeruginosa biofilm-forming ability. We analyzed genes which could be related to biofilm forming based on the available literature.

Our study showed that only two virulence factor genes (fliC in canine strains, and nan 1 in feline strains) could be linked to the biofilm-forming ability. The remaining genes occurred similarly often in both types of P. aeruginosa strains - the ppyR gene in virtually all examined strains, fliC and pslA in slightly more than a half, whereas nan 1 and pelA were in less than a half of examined strains.

Milivojevic et al. [26] and Sharma et al. [5] previously showed that P. aeruginosa isolates had biofilm forming ability in $93 \%$ and $89 \%$ of dogs, respectively. This phenomenon was supported by our study, in which $86 \%$ and $91 \%$ of isolates in cats and dogs were biofilm producers, respectively. In our study, $34.9 \%$ and $33.9 \%$ of isolates in dogs and cats, respectively, were strong biofilm-producers. However, we are not able to compare the strength of biofilm-forming ability with our research because Milivojevic et al. [26] used PAO1 as a cut-off value of the MTP test, while we established the cut-off value arbitrarily. Results of biofilm-forming ability in humans and animals in the study by the mentioned authors were similar. This conclusion supports the necessity of controlling the occurrence and biofilm-forming ability of $P$. aeruginosa in companion animals.

In contrast to our study, Pye et al. [27] classified only $40 \%$ of $P$. aeruginosa samples isolated from dogs as biofilm formers. This discrepancy with our results might be attributed to the use of lysogeny broth (LB) medium. Wijesinghe et al. [28] showed that, compared to LB medium, BHI performed better at analyzing in vitro biofilm growth. A difference between Pye et al. [27] and our results may be associated with the period of time when the studies were carried out as the genetic content of $P$. aeruginosa strains collected could be different between the two studies.

The presence of pelA, pslA, ppyR, fliC, and nan1 genes has been previously associated with biofilm formation in human medicine $[18,19,26]$. However, the fact that they are also detectable in isolates from companion animals implies that they are universal. Samad et al. [29] obtained a similar prevalence for the pelA gene (44\%) to our study, with $40 \%$ of $P$. aeruginosa samples from dogs harboring it. Higher prevalence might be associated with the origin of collected samples because Samad et al. [29] collected both clinical and environmental samples. In our study, only samples from companion animals were collected.

Ertugrul et al. [30] detected fliC gene in $60 \%$ of samples, and this result is similar to ours. We detected fliC in the P. aeruginosa samples of $60 \%$ and $70 \%$ of dogs and cats, respectively. We showed that the detection of two genes in dogs and cats could be used to determine $P$. aeruginosa biofilm-forming ability. The presence of fliC in dogs and the absence of nan 1 in cats was significantly associated with biofilm formation. This latter finding could result from unknown elements in the quorum sensing mechanism for P. aeruginosa infection in cats. It could be related to nan1 gene occurrence and the planktonic form of $P$. aeruginosa that is responsible for acute infection. Lanotte et al. [14] showed that, although 
not statistically significant, the prevalence of the nan 1 gene rose in cases with worse clinical status. The authors detected nan1 in the P. aeruginosa strain of $57 \%$ of patients with cystic fibrosis with good and excellent clinical status, and in $71 \%$ of patients with poor or weak clinical status.

Our study showed that cats were closer to the cystic fibrosis human model compared to dogs, because $83 \%$ of strains originated from the respiratory tract, compared to only $17 \%$ for dogs. We compared our results regarding nan 1 and fliC genes with human data because no studies on these genes in companion animals have so far been published. To our knowledge, this study is the first to report the detection of nan 1 and fliC genes in dogs and cats. However, our results on cats are at odds with the result obtained by Soong et al. [15] in humans, as a positive correlation between biofilm formation and neuraminidase production was observed in this study. This result might be attributed to the contribution of initial colonization in the airway. Thus, different neuraminidase might be produced under genetic control in particular species.

\section{Conclusions}

Our study indicates that analysis of $P$. aeruginosa biofilm-forming ability may be based on detection of selected virulence factor genes. The development of a simple marker for quick PCR gene detection could help support the treatment of $P$. aeruginosa infections both in human and animal medicine. It has to be stressed that this is a preliminary study, and further investigations and analyses are essential to introduce these results into medical practice.

Author Contributions: All authors of this research paper have directly participated in the planning and/or execution and/or analysis of this study. D.P. wrote the manuscript, designed the research, table and figures, and analyzed data; M.C. provided statistical analysis and corrected the manuscript, tables and figures; K.B. corrected the manuscript; K.R. contributed to the design of the research, analyzed data and supervised the findings of this work. All authors have read and agreed to the published version of the manuscript.

Funding: The APC/BPC is financed/co-financed by Wroclaw University of Environmental and Life Sciences.

Institutional Review Board Statement: The samples used in this study originally came from the samples used as material for routine diagnostics.

Informed Consent Statement: This study was provided based on material from VETLAB Ltd. in Wroclaw. All animals had their own veterinarian who was responsible for providing information about potential zoonotic risk. The study did not involve humans.

Data Availability Statement: The datasets used and/or analyzed during the current study are available via e-mail from the corresponding author on reasonable request.

Acknowledgments: The authors thank Katarzyna Płoneczka-Janeczko and Kamila Bobrek for help in the laboratory work and the technicians from the Diagnostic Laboratory EPI-VET of the Faculty of Veterinary Medicine in Wroclaw, and Józef Galli from VETLAB Ltd. in Wroclaw, who performed part of the laboratory work.

Conflicts of Interest: The authors declare no conflict of interest. The funders had no role in the design of the study, the collection, analyses, or interpretation of data, writing of the manuscript, or the decision to publish the results.

\section{References}

1. Da Silva, L.C.A.; Pessoa, D.A.; Maia, L.A.; Matos, R.A.; Macêdo, M.M. Systemic infection by Pseudomonas aeruginosa in a dog. Act. Sci. Vet. 2016, 44, 1-5. [CrossRef]

2. Hillier, A.; Alcorn, J.R.; Cole, L.K.; Kowalski, J.J. Pyoderma caused by Pseudomonas aeruginosa infection in dogs: 20 cases. Vet. Dermatol. 2006, 17, 432-439. [CrossRef] [PubMed]

3. Robinson, V.H.; Paterson, S.; Bennett, C.; Steen, S.I. Biofilm production of Pseudomonas spp. isolates from canine otitis in three different enrichment broths. Vet. Dermatol. 2019, 30, 218-e67. [CrossRef] [PubMed] 
4. Prado, M.R.; Rocha, M.F.G.; Brito, É.H.S.; Girão, M.D.; Monteiro, A.J.; Teixeira, M.F.S.; Sidrim, J.J.C. Survey of bacterial microorganisms in the conjunctival sac of clinically normal dogs and dogs with ulcerative keratitis in Fortaleza, Ceará, Brazil. Vet. Ophthalmol. 2005, 8, 33-37. [CrossRef] [PubMed]

5. Sharma, D.; Pakravanm, N.; Pritchard, J.C.; Hartmann, F.A.; Young, K.M. Mucoid Pseudomonas aeruginosa infection in a cat with severe chronic rhinosinusitis. Vet. Clin. Pathol. 2019, 48, 300-304. [CrossRef]

6. Chawnan, N.; Na Lampang, K.; Mektrirat, R.; Awaiwanont, N.; Thongkorn, K. Cultivation of bacterial pathogens and antimicrobial resistance in canine periapical tooth abscesses. Vet. Integr. Sci. 2021, 19, 513-524. [CrossRef]

7. Riggio, M.P.; Lennon, A.; Taylor, D.J.; Bennett, D. Molecular identification of bacteria associated with canine periodontal disease Vet. Microbiol. 2011, 3-4, 394-400.

8. Shehab, Z.; Al-Rubaii, B. Correlation of nan1 (Neuraminidase) and production of some type III secretion system in clinical isolates of Pseudomonas aeruginosa. Biosci. Res. 2018, 15, 1729-1738.

9. Paterson, S. Biofilms: Their importance in veterinary medicine. Companion Anim. 2017, 22, 659-668. [CrossRef]

10. Vestby, L.K.; Grønseth, T.; Simm, R.; Nesse, L.L. Bacterial Biofilm and its Role in the Pathogenesis of Disease. Antibiotics 2020, 9, 59. [CrossRef]

11. Wei, Q.; Ma, L.Z. Biofilm Matrix and Its Regulation in Pseudomonas aeruginosa. Int. J. Mol. Sci. 2013, 14, 20983-21005. [CrossRef] [PubMed]

12. Jyot, J.; Ramphal, R. Flagella and Pili of Pseudomonas aeruginosa. In Pseudomonas: Model Organism, Pathogen, Cell Factory; Wiley-VCH: Weinheim, Germany, 2008; pp. 85-108.

13. Mahenthiralingam, E.; Campbell, M.E.; Speert, D.P. Nonmotility and phagocytic resistance of Pseudomonas aeruginosa isolates from chronically colonized patients with cystic fibrosis. Infect. Immun. 1994, 62, 596-605. [CrossRef]

14. Lanotte, P.; Watt, S.; Mereghetti, L.; Dartiguelongue, N.; Rastegar-Lari, A.; Goudeau, A.; Quentin, R. Genetic features of Pseudomonas aeruginosa isolates from cystic fibrosis patients compared with those of isolates from other origins. J. Med. Microbiol. 2004, 53, 73-81. [CrossRef]

15. Soong, G.; Muir, A.; Gomez, M.I.; Waks, J.; Reddy, B.; Planet, P.; Singh, P.K.; Kanetko, Y.; Wolfgang, M.C.; Hsiao, Y.-S.; et al. Bacterial neuraminidase facilitates mucosal infection by participating in biofilm production. J. Clin. Investig. 2006, 116, $2297-2305$. [CrossRef]

16. Wolska, K.; Kot, B.; Mioduszewska, H.; Sempruch, C.; Borkowska, L.; Rymuza, K. Occurrence of the nan1 gene and adhesion of Pseudomonas aeruginosa isolates to human buccal epithelial cells. Biol. Lett. 2012, 49, 59-64. [CrossRef]

17. De Vos, D.; Lim, A.; Pirnay, J.P.; Struelens, M.; Vandenvelde, C.; Duinslaeger, L.; Vanderkelen, A.; Cornelis, P. Direct detection and identification of Pseudomonas aeruginosa in clinical samples such as skin biopsy specimens and expectorations by multiplex PCR based on two outer membrane lipoprotein genes, oprI and oprL. J. Clin. Microbiol. 1997, 35, 1295-1299. [CrossRef] [PubMed]

18. Ghadaksaz, A.; Fooladi, A.A.I.; Hosseini, H.M.; Amin, M. The prevalence of some Pseudomonas virulence genes related to biofilm formation and alginate production among clinical isolates. J. Appl. Biomed. 2015, 13, 61-68. [CrossRef]

19. Sattari, M.; Godarzi, G.H. The recognizing of fli C gene in Pseudomonas aeruginosa isolated from clinical sample with PCR. Med. Lab. J. 2009, 3.

20. O'Toole, G.A. Microtiter Dish Biofilm Formation Assay. J. Vis. Exp. 2011, 47, e2437. [CrossRef]

21. Darwish, S.F.; Asfour, H.A.E. Investigation of biofilm forming ability in staphylococci causing bovine mastitis using phenotypic and genotypic assays. Sci. World J. 2013, 2013, 1-9. [CrossRef]

22. Agresti, A. An Introduction to Categorical Data Analysis, 2nd ed.; John Wiley \& Sons: London, UK, 2007; pp. 41-45.

23. Newcombe, R.G.; Altman, D.G. Proportions and Their Differences. In Statistics with Confidence: Confidence Intervals and Statistical Guidelines, 2nd ed.; Altman, D.G., Machin, D., Bryant, T.N., Gardner, M.J., Eds.; BMJ Book: London, UK, 2000 ; pp. $45-48$.

24. Barnard, N.; Foster, A. Pseudomonas otitis in dogs: A general practitioner's guide to treatment. Practice 2017, 39, 386-398. [CrossRef]

25. Ceri, H.; Olson, M.; Morck, D.; Storey, D.; Read, R.; Buret, A.; Olson, B. The MBEC assay system: Multiple equivalent biofilms for antibiotic and biocide susceptibility testing. Method. Enzymol. 2001, 337, 377-385.

26. Milivojevic, D.; Šumonja, N.; Medić, S.; Pavic, A.; Moric, I.; Vasiljevic, B.; Senerovic, L.; Nikodinovic-Runic, J. Biofilm-forming ability and infection potential of Pseudomonas aeruginosa strains isolated from animals and humans. Pathog. Dis. 2018, 76, 1-14. [CrossRef] [PubMed]

27. Pye, C.C.; Yu, A.A.; Weese, J.S. Evaluation of biofilm production by Pseudomonas aeruginosa from canine ears and the impact of biofilm on antimicrobial susceptibility in vitro. Vet. Dermatol. 2013, 24, 446-449. [CrossRef] [PubMed]

28. Wijesinghe, G.; Dilhari, A.; Gayani, B.; Kottegoda, N.; Samaranayake, L.; Weerasekera, M. Influence of laboratory culture media on in vitro growth, adhesion, and biofilm formation of Pseudomonas aeruginosa and staphylococcus aureus. Med. Princ. Pract. 2018, 28, 28-35. [CrossRef] [PubMed]

29. Samad, A.; Khan, A.A.; Sajid, M.; Zahra, R. Assessment of biofilm formation by Pseudomonas aeruginosa and hydrodynamic evaluation of microtiter plate assay. J. Pak. Med Assoc. 2019, 69, 666-671.

30. Ertugrul, B.; Oryasin, E.; Lipsky, B.A.; Willke, A.; Bozdogan, B. Virulence genes fliC, toxA and phzS are common among Pseudomonas aeruginosa isolates from diabetic foot infections. Infect. Dis. 2017, 50, 273-279. [CrossRef] 